\title{
Suitability of Vermiculite and Rice Husk Ash as Raw Materials for Production of Ceramic Tiles
}

\author{
Said Abeid*, Seungyong Eugene Park \\ Email address: \\ abeids@nm-aist.ac.tz (S. Abeid), eugene.park@nm-aist.ac.tz (S. E. Park) \\ ${ }^{*}$ Corresponding author
}

Department of Materials Science and Engineering, the Nelson Mandela African Institution of Science and Technology, Arusha, Tanzania

\section{To cite this article:}

Said Abeid, Seungyong Eugene Park. Suitability of Vermiculite and Rice Husk Ash as Raw Materials for Production of Ceramic Tiles. International Journal of Materials Science and Applications. Vol. 7, No. 2, 2018, pp. 39-48. doi: 10.11648/j.ijmsa.20180702.12

Received: December 17, 2017; Accepted: January 9, 2018; Published: February 3, 2018

\begin{abstract}
The challenging issues in ceramic tiles are low mechanical strength, thermal discomfort and high production costs. And in most efforts to improve strength, emphasis has been placed on minimization of quartz content in the ceramic tiles formula. This is due to $\beta-\alpha$ phase inversion of quartz which occurs at $573^{\circ} \mathrm{C}$ during cooling resulting to the development of stresses which initiate fracture and affects the strength of the final body. The objective of this work was to evaluate the possibility of using vermiculite and rice husk ash (RHA) in the composition of ceramic tile body. Initially, a typical ceramic body composed of the mixture of vermiculite and RHA batched with clay, feldspar, quartz and kaolin was prepared. Ceramic bodies were then obtained from this ceramic mixture by pressing samples at a forming pressure of $35 \mathrm{MPa}$. These bodies were then fired at $1180^{\circ} \mathrm{C}$ in a laboratory furnace and finally the changes in the physical and mechanical properties caused by the introduction of vermiculite and RHA were tested and evaluated. The chemical composition of the raw samples was analyzed by X-ray fluorescence (XRF) while the phase composition was investigated using X-ray diffraction (XRD). The morphology of the powdered samples was studied by using Scanning electron microscopy (SEM). The bulk density and open porosity of the sintered ceramic bodies were evaluated using Archimedes 'principle while the flexural rupture strength was determined by the three point bending test method. The major chemical compounds in vermiculite raw sample were $\mathrm{SiO}_{2}, \mathrm{Al}_{2} \mathrm{O}_{3}$ and $\mathrm{Fe}_{2} \mathrm{O}_{3}$ while RHA sample was found to contain mainly $\mathrm{SiO}_{2}$. From the XRD analysis, vermiculite sample had crystalline vermiculite while RHA sample had amorphous silica at low temperature below $900^{\circ} \mathrm{C}$ and crystallized (tridymite) above $900^{\circ} \mathrm{C}$. The results from physical and mechanical properties tests show that with addition of vermiculite and RHA, the percentage of porosity, water absorption and linear shrinkage were increasing while the bulk density and bending strength of the fired ceramic bodies decreased. Among the studied compositions tile bodies made from a blend containing $20 \% \mathrm{wt}$. vermiculite and $5 \%$ wt. RHA were found to have the best properties for ceramic tiles applications. For this combination the percentage of porosity, water absorption and linear shrinkage were $12.08 \%, 7.60 \%$ and $3.29 \%$ while the bulk density and bending strength were $1.88 \mathrm{~g} / \mathrm{cm}^{3}$ and 18.84 MPa respectively. These values were close to the required standards of wall and floor tiles.
\end{abstract}

Keywords: Vermiculite, Tridymite, Amorphous, Crystalline, Flexural Strength

\section{Introduction}

A typical ceramic tile composition will consist of $50 \%$ clay which imparts rigidity to the ceramic body, $25 \%$ quartz which lowers both drying and firing shrinkage and $25 \%$ feldspar which serves as a flux and also provides a glassy phase in the microstructure. Mullite and glass constitute the major phases of final ceramic product. Other constituents of the fired ceramic body in minor levels are quartz, cristobalite, tridymite and corundum [1]. Quartz and kaolin are mostly preferred as a source of silica and alumina respectively and they have a great influence on the mechanical strength of ceramic tiles because when they are mixed and fired at very high temperature close to their melting points they form a very strong alumina-silica phase called mullite which controls the strength of the ceramic body. But quartz grains embedded in the glassy matrix have a deleterious effect on the mechanical strength mainly because of its $\alpha-\beta$ phase transformation during cooling resulting to the development of stress which initiate fracture [2,3]. Also, most of ceramic 
products especially tiles are produced at a temperature above $1000^{\circ} \mathrm{C}$ which is associated with high energy consumptions and raises the production costs. For these reasons this study was based on testing and evaluating the suitability of vermiculite and RHA as additives in the in production of ceramic tiles by considering strength as the central objective. Vermiculite is a clay minerals produced by the decompositions of mica and occurs as large crystals of micalike lamellar structure that quickly expands on heating to produce a lightweight material [4]. In Tanzania vermiculite can be found in places like Kalalani Tanga and Mikese Morogoro. In its expanded form, vermiculite has a very low density and thermal conductivity, which makes it attractive for use as a lightweight construction aggregate, and thermal insulation filler [5]. Partial replacement of quartz by RHA is expected to reduce the possibility of $\beta$ to $\alpha$ phase inversion of quartz which occurs at $573^{\circ} \mathrm{C}$ during cooling which leads to decrease in quartz particles volume and thus cracks in the ceramic body. The use of RHA in ceramic body have been proven to improve the strength compared to the body without RHA [3]. The reduction in the vitrification temperature of the mixes with addition of both vermiculite and RHA during firing would also contribute significantly to the economical production of ceramic tiles due to low energy consumptions although the temperature has to be high enough in order to achieve an acceptable strength. Currently no research has been done to test the potential of the combination of both vermiculite and RHA in ceramic tiles applications. In this study the suitability of vermiculite and rice husk ash as raw materials for production of ceramic tiles was tested and evaluated.

\section{Materials and Methods}

\subsection{Raw Materials Collection}

Materials that were involved in this study include vermiculite samples $\mathrm{V}_{\mathrm{K} 1}, \mathrm{~V}_{\mathrm{K} 2}$ and $\mathrm{V}_{\mathrm{K} 3}$ (Figure 1) taken from three mining sites; Red Garmet, Red Safaya, and Pink Safaya respectively all found at Kalalani village in Tanga region eastern part of Tanzania. Rice husk samples were taken from Bahi district in Dodoma region central part of Tanzania. Pugu kaolin, Same clay, quartz and feldspar were obtained from Geological Survey of Tanzania Laboratory in Dodoma.
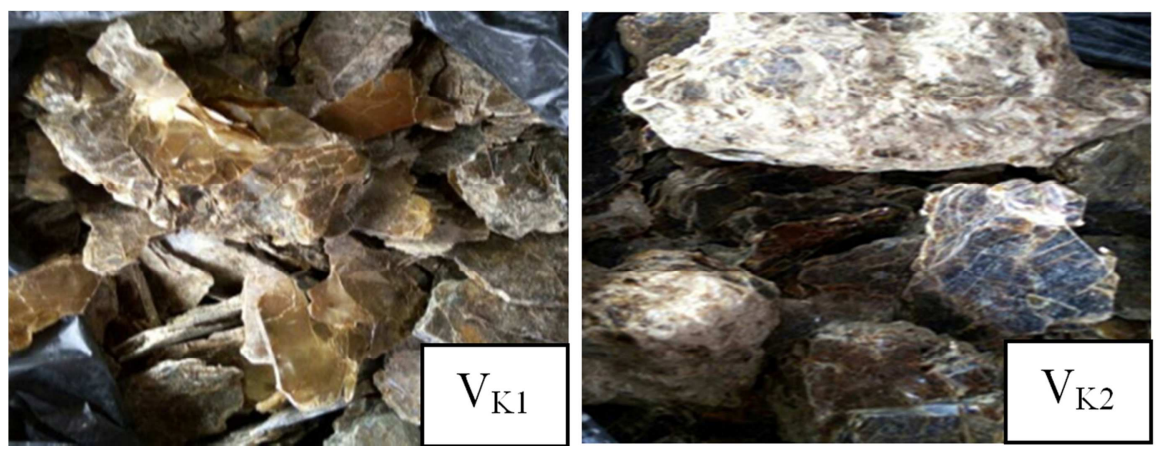

Figure 1. Photomicrographs of vermiculite samples.

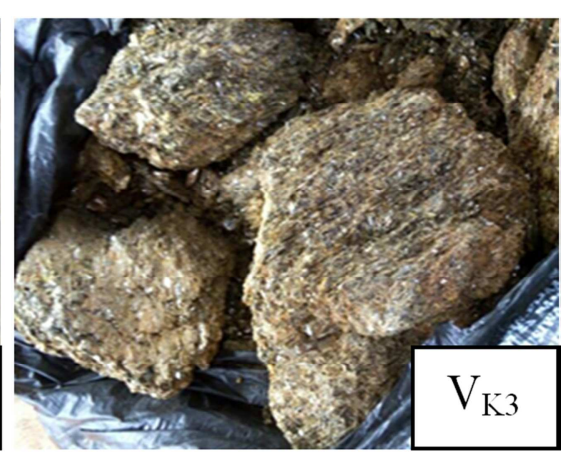

\subsection{Sample Preparations and Pretreatment of Ceramic Constituents}

The procedure for preparing rice husk powder consist of washing RH in distilled water in order to remove clay and rock impurities and subsequently drying in an oven at $120^{\circ} \mathrm{C}$ for $12 \mathrm{~h}$. Then $30 \mathrm{~g}$ of dry husk was reacted with $2 \mathrm{M} \mathrm{HCl}$ at $25^{\circ} \mathrm{C}$ in a $500 \mathrm{~mL}$ under constant agitation for $2 \mathrm{~h}$. This was done to remove metallic impurities and organics contained in rice husk before calcination. The husk was then washed with distilled water till neutral $\mathrm{pH}$ was obtained and then dried. The dried $\mathrm{RH}$ was later heated at $700^{\circ} \mathrm{C}$ for $2 \mathrm{~h}$ to at a heating rate of $10^{\circ} \mathrm{C} / \mathrm{min}$ under air atmosphere to obtain carbon free white ash. At $700^{\circ} \mathrm{C}$ and below, ash rich in amorphous silica is formed which is highly reactive. Above $700^{\circ} \mathrm{C}$, crystalline silica which is far less reactive is obtained. On the other hand, Pugu kaolin, vermiculite, quartz, and feldspar samples were separately dried at $130^{\circ} \mathrm{C}$ in the oven for $24 \mathrm{~h}$ and then ground by using ball mill for $6 \mathrm{~h}$. The powdered samples were sifted through a sieve of $150 \mu \mathrm{m}$ pore size. Grinding and sieving were repeated until almost all the materials passed through the sieve.

\subsection{Chemical, Mineralogical and Microstructural Analyses of Raw Materials}

The chemical compositions of raw materials were studied at Geological Survey of Tanzania (GST) Laboratory using XRay Fluorescence (XRF) PANalytical, Minipal4 (PW4030)$\mathrm{Rh}$ X-Ray Tube, which was operating at $30 \mathrm{kV}, 0.002 \mathrm{~mA}$. The amorphous and crystalline structure of vermiculite and RHA samples were identified by using Ultima IV Rigaku diffractometer operating at tube voltage and current at $40 \mathrm{kV}$ and $44 \mathrm{~mA}$, respectively using monochromatic $\mathrm{Cu}-\mathrm{K} \alpha$ radiation. Diffraction patterns were recorded by scanning from $5^{\circ}$ to $75^{\circ}(2 \theta / \theta)$ in steps of $0.02^{\circ}(2 \theta / \theta)$ at a rate of $2 \mathrm{sec} / \mathrm{step}$. The morphological features were studied by using Scanning electron microscopy (FEI Nova NanoSEM 450, $2 \mathrm{kV}$ ). The SEM and XRD analyses were all carried out at the University of Connecticut, USA.

\subsection{Batch Composition}

Vermiculite was gradually incorporated into the ceramic samples with a composition range of 20 to $35 \%$ wt. to make 
the first batch of tile samples with vermiculite, $\mathrm{T}_{2}$ to $\mathrm{T}_{5}$. Then 5 to $20 \%$ wt. of RHA was added together with 20 to $35 \%$ wt. of vermiculite to complete the second batch of tile samples, $\mathrm{T}_{6}$ to $\mathrm{T}_{9}$. The first test sample $\mathrm{T}_{1}$ used as a control sample contained neither vermiculite nor RHA (Table 1). The compositions were mixed with 5 to $6 \%$ wt. water using ball mill for $90 \mathrm{~min}$.

Table 1. Mix proportion of raw materials (\%wt.).

\begin{tabular}{|c|c|c|c|c|c|c|}
\hline Tile coc & Vermicu & Pugu Ka & Same Cl & RHA & Quartz & Feldspa \\
\hline $\mathrm{T}_{1}$ & - & 10 & 60 & - & 10 & 20 \\
\hline $\mathrm{T}_{2}$ & 201 & 10 & 40 & - & 101 & 20 \\
\hline $\mathrm{T}_{3}$ & 25 & 10 & 35 & - & 10 & 20 \\
\hline $\mathrm{T}_{4}$ & 30 & 10 & 30 & - & 10 & 20 \\
\hline $\mathrm{T}_{5}$ & 35 & 10 & 25 & - & 10 & 20 \\
\hline $\mathrm{T}_{6}$ & 20 & 10 & 35 & 5 & 10 & 20 \\
\hline $\mathrm{T}_{7}$ & 25 & 10 & 30 & 10 & 5 & 20 \\
\hline $\mathrm{T}_{8}$ & 30 & 10 & 22.5 & 15 & 2.5 & 20 \\
\hline $\mathrm{T}_{9}$ & 35 & 10 & 15 & 20 & - & 20 \\
\hline
\end{tabular}

\subsection{Preparation of Ceramic Green Bodies}

Discs-shape ceramic bodies of $3 \mathrm{~cm}$ diameter and $8 \mathrm{~mm}$ in thickness were prepared by pressing samples at a forming pressure of $35 \mathrm{MPa}$ in order to measure the physical properties while square tiles of $140 \times 64 \times 14 \mathrm{~mm}^{3}$ were prepared for bending strength measurements (Figure 2a). The tile samples were subsequently oven-dried at $110^{\circ} \mathrm{C}$ for $24 \mathrm{~h}$ followed by cooling at room temperature for $1 \mathrm{~h}$. The dimension and weight of each green (dried) body was recorded before sintering.

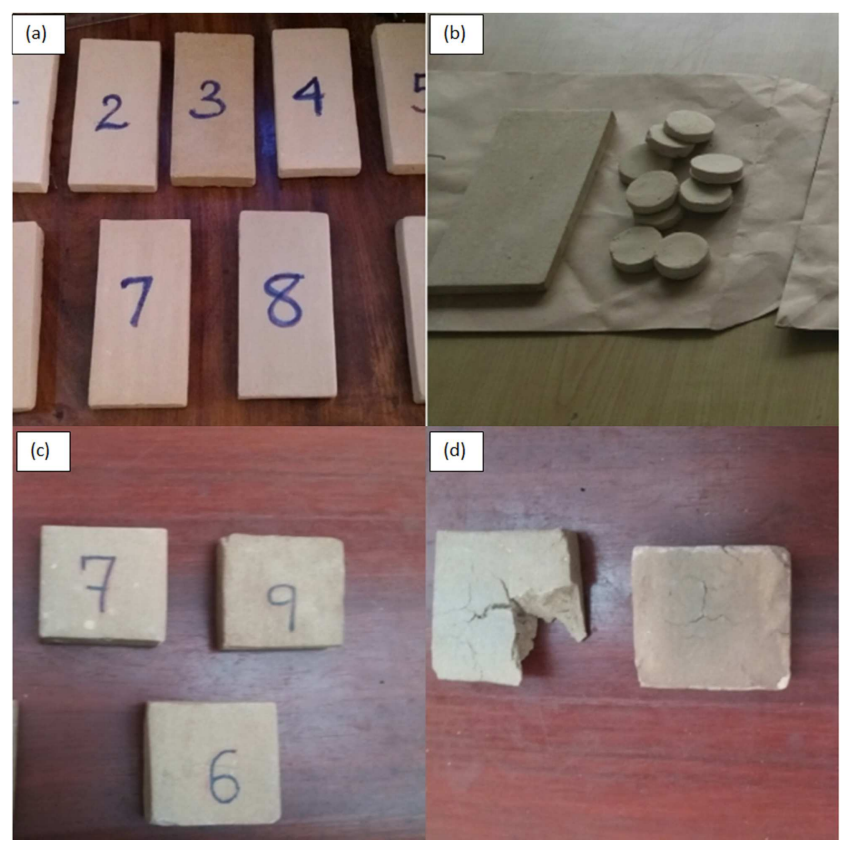

Figure 2. Disc- and tile-shaped bodies fabricated using vermiculite and RHA for physical and mechanical properties tests (a) green bodies (b) fired bodies (c) fired and labelled bodies (d) fired bodies with visual defects such as cracks, lamination and surface deformation.

\subsection{Firing of Ceramic Green Bodies}

The ceramic bodies were then fired at $1180^{\circ} \mathrm{C}$ for $2 \mathrm{~h}$ soaking time, at a heating rate of $50^{\circ} \mathrm{C}$ per minute in a Carbolite box furnace (RHF 14/8 Model) manufactured by Keison products Inc, UK. The firing parameters tests were all performed at Tanzania Portland Cement Company Limited (TPCC). After firing, the samples were permitted to cool down to room temperature inside the kiln for $24 \mathrm{~h}$ and then the dimensions and weights of the fired tile bodies were recorded. Finally the fired bodies (Figure 2b) were labeled (Figure 2c) and then stored in airtight containers ready for mechanical tests and further characterizations.

\subsection{Determination of Physical and Mechanical Properties of Tile Bodies}

Fired ceramic bodies were inspected for any visual defects such as cracks, lamination and surface deformation. Thus, good quality ceramic bodies were selected and used for determination of the physical and mechanical properties. The physical and mechanical properties tests of the fired tile bodies were all carried out at Tanzania Bureau of Standards (TBS) - Materials testing laboratory.

The bulk density and open porosity of the sintered ceramic bodies were evaluated using Archimedes 'principle which involved drying tiles in an oven at $110^{\circ} \mathrm{C}$ for $24 \mathrm{~h}$ and cooling in desiccators. The dry mass of the tiles $(\mathrm{Wd})$ was then measured, followed by water impregnation, which involved boiling tiles in distilled water for $5 \mathrm{~h}$ and then left soaked in water for an additional $24 \mathrm{~h}$ at room temperature. After impregnation, the suspended mass (S) of each tile body was recorded. The saturated mass (W) was measured after removing all excess water from the surface by using moistened cotton cloth. The bulk density was calculated using the formula;

$$
\text { B. } D=\left[\frac{W d}{W-S}\right] . D[6]
$$

While porosity was given by the following expression;

$$
\mathrm{P}=\left[\frac{\mathrm{W}-\mathrm{Wd}}{\mathrm{W}-\mathrm{S}}\right] \cdot 100 \%[6]
$$

Where $\mathrm{W}_{\mathrm{d}}$ was dry weight, $\mathrm{W}$ was soaked weight, $\mathrm{S}$ was suspended weight, and D was density of water. Experiments were carried out at a room temperature of $18^{\circ} \mathrm{C}$, in which the density of water was $1.00 \mathrm{~g} / \mathrm{cm}^{3}$. The water absorption A was calculated as the ratio of the mass of water absorbed to the mass of the dry specimen and given by the expression

$$
A=\left[\frac{W-W d}{W d}\right] \cdot 100 \%[7]
$$

While linear shrinkage (L. S) was calculated by measuring dimensions of the prepared specimen before and after firing hence;

$$
\text { L. } S=\left[\frac{\mathrm{Lg}-\mathrm{Lf}}{\mathrm{Lg}}\right] \cdot 100 \%[8]
$$

Where $\mathrm{L}_{\mathrm{g}}$ and $\mathrm{L}_{\mathrm{f}}$ were the lengths (mm) of green and fired tile bodies, respectively. The flexural rupture strength was 
determined by the three point bending test in a bending strength tester (MEGA 10-200-10 DS) manufactured by Prufsyteme Inc. in Germany, 2001.

\section{Results and Discussion}

\subsection{Chemical Composition and Phase Analysis of the Raw Materials}

The presence of various compounds within the raw materials can be seen in Table 2. It is evident that $\mathrm{SiO}_{2}$ was the major composition in the raw materials with $92.1 \mathrm{wt} . \%$ in RHA, 97.7 wt.\% in quartz, and 62.10 wt.\% in vermiculite. Alumina was high in Pugu kaolin with 30.30 wt.\% and lowest in vermiculite with 9.20 wt.\% while RHA and quartz showed no any indication of alumina. Silica and alumina in the raw materials are to be taken into account as they play a very important role during sintering. Silica is a glass former while alumina is a refractory which gives strength and durability to a ceramic body. Vermiculate samples showed high percentage of $\mathrm{Fe}_{2} \mathrm{O}_{3}$ at 18.70 wt.\%. High content of Iron affects thermal comfort of the final ceramic body due to increase of thermal conductivity and effusivity. The flux oxide, $\mathrm{K}_{2} \mathrm{O}$ which is essential for liquid phase formation and lowering the melting points of silica in the ceramic body, was high in feldspar than in any other raw materials with 23.5 wt.\% although $\mathrm{Na}_{2} \mathrm{O}$ was only present in Pugu kaolin and vermiculite in a small amount less than $1 \mathrm{wt} . \%$. The opacifier $\mathrm{TiO}_{2}$ which makes the ceramic body opaque was high in vermiculite and Pugu kaolin with 1.83 wt. $\%$ and 1.22 wt.\% respectively, but was too low in the remaining samples with less than 1 wt.\%. The alkaline earth oxide, $\mathrm{CaO}$ was present in all raw samples except in feldspar and quartz; and the highest amount was obtained in RHA with 2.98 wt. $\%$ while $\mathrm{MgO}$ was present in vermiculite only with 6.10 wt.\%. The low earth-alkaline oxides $(\mathrm{CaO}$ and $\mathrm{MgO})$ content for Pugu kaolin and Same clay indicates that the studied clays are poor in carbonates [7]. The fluxing oxides and colorants must be maintained at low amount to avoid undesired color and the possibility of excessive fluxing in the ceramic product [8]. In this study RHA had a chemical composition of $92.10 \mathrm{wt} . \%$ silica which was too close to other authors' findings 93.70 wt.\% [3], 93.67wt.\% [9], and 94.95 wt.\% [10]. Also the amount of silica in Kalalani vermiculite was close to the required standard for production of ceramic tiles with 47.3 to 79.3 wt.\% according to [8]. Vermiculite raw sample shows a loss on ignition of about $5.76 \%$ which was the highest compared to that of the remaining samples. This value was related to the presence of organic residues where the decomposition of carbonates and sulphates produced a significant weight loss at a temperature above $1000^{\circ} \mathrm{C}$ (Table 2).

Table 2. Chemical composition of raw materials (wt.\%).

\begin{tabular}{|c|c|c|c|c|c|c|}
\hline & Vermiculite & Pugu kaolin & Same Clay & RHA & Feldspar & Quartz \\
\hline $\mathrm{SiO}_{2}$ & 62.10 & 60.00 & 60.40 & 92.10 & 57.10 & 97.70 \\
\hline $\mathrm{Al}_{2} \mathrm{O}_{3}$ & 9.20 & 30.30 & 13.90 & - & 14.00 & - \\
\hline $\mathrm{Fe}_{2} \mathrm{O}_{3}$ & 18.70 & 3.95 & 1.40 & 2.26 & 1.05 & - \\
\hline $\mathrm{CaO}$ & 0.81 & 0.39 & 0.02 & 2.98 & - & - \\
\hline $\mathrm{MgO}$ & 6.10 & - & - & - & - & - \\
\hline $\mathrm{Na}_{2} \mathrm{O}$ & 0.05 & 0.04 & - & - & - & - \\
\hline $\mathrm{K}_{2} \mathrm{O}$ & 0.11 & 2.14 & 22.60 & 0.96 & 23.50 & - \\
\hline LOI & 5.76 & 1.96 & 1.56 & 1.52 & 4.35 & 2.30 \\
\hline
\end{tabular}

Figure 3 shows the X-ray diffractograms of the vermiculite and RHA samples. The XRD patterns of raw vermiculite show the presence of vermiculite as the major phase which was identified by peaks around $5^{\circ}$ and $31.5^{\circ} 2 \theta$ (Figure 3a). These results are close to XRD results of Kalalani vermiculite according to work done by [11] which showed vermiculite as the only phases in the sample. In Figure $3 \mathrm{~b}$ the evolution of the crystalline phase from the amorphous silica present in the RHA can be seen. The XRD pattern shows the presence of tridymite as the major phase which was identified by peaks around $20.76^{\circ}$ and $39.49^{\circ} 2 \theta$. According to [9], silica of RHA is amorphous at low temperatures between 700 and $800^{\circ} \mathrm{C}$. Firing RHA at $900^{\circ} \mathrm{C}$ and above produces crystal phases of two forms, cristobalite and tridymite which are less reactive. The transformation of amorphous silica to a cristobalite phase occurs at a temperature interval between 550 and $950^{\circ} \mathrm{C}$ [12].

The SEM micrographs of raw vermiculite and RHA samples
(Figure 4) show the morphology of the vermiculite and RHA particles. Some of the detected phases are identified based on local chemical analysis by EDS. Figure 4(a) shows the morphology of vermiculite sample containing flakes with individual layer crystals which were very closely spaced. The milled vermiculite flakes had a size range of smaller than $150 \mu \mathrm{m}$. The images show that vermiculite was more porous than porcelain and hence increasing in vermiculite content cause an increase in porosity size and amount. These results had a good agreement with bulk density and porosity results of the tile samples described in Part 3.2 of this article. Figure 4(b) shows the scanning electron microscopy of RHA powder which indicates that the ash was siliceous in nature with a porous structure and consists of quartz grains of various sizes and irregular shapes; these results agree with other authors as per [3], [13] and [14]. The porous nature of RHA and its honeycombed structure is responsible for its high specific surface [13] and this is a good indication for its suitability in ceramic tiles applications. 

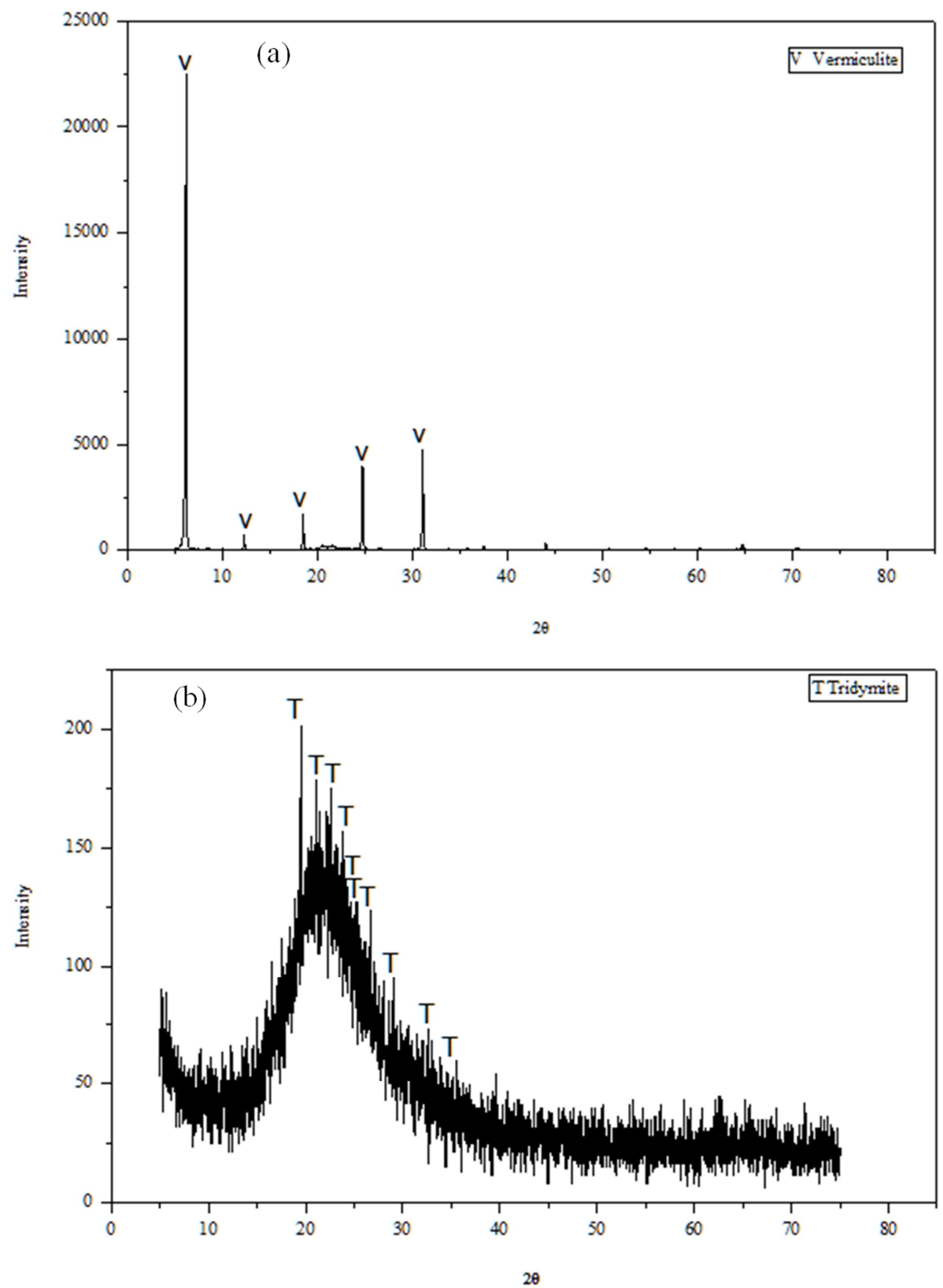

Figure 3. X-ray diffraction of (a) vermiculite (b) RHA raw samples.

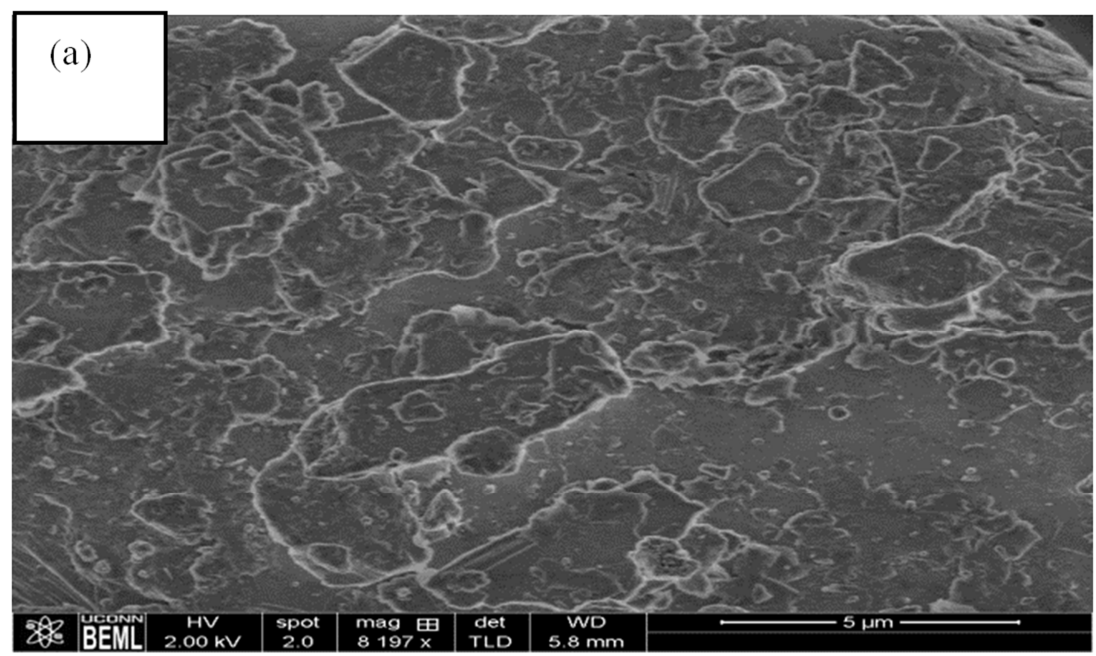




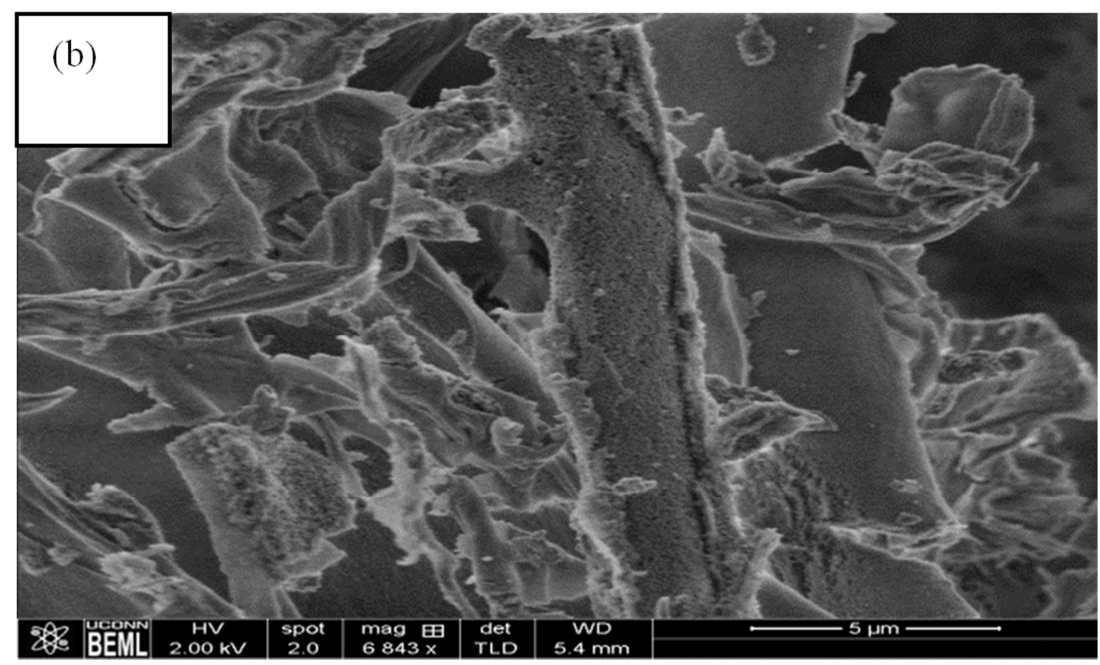

Figure 4. SEM micrographs of (a) vermiculite (b) RHA raw samples.

\subsection{Physical and Mechanical Properties of the Fired Tile Bodies}

Results for the physical and mechanical properties tests of the ceramic bodies were presented and summarised in Table 3 . The symbols WA, P, BD, LS and $\partial_{f s}$ are water absorption, porosity, bulk density, linear shrinkage and flexural strength respectively.

Table 3. Physical and mechanical properties of tile bodies sintered at $1180^{\circ} \mathrm{C}$.

\begin{tabular}{|c|c|c|c|c|c|}
\hline Tile code & WA (\%) & $\mathbf{P}(\%)$ & $\mathrm{BD}\left(\mathrm{g} / \mathrm{cm}^{3}\right)$ & LS (\%) & $\partial_{\mathrm{fs}}(\mathrm{MPa})$ \\
\hline $\mathrm{T}_{1}$ & 2.17 & 5.72 & 2.15 & 1.02 & 28.86 \\
\hline $\mathrm{T}_{2}$ & 8.21 & 13.88 & 1.74 & 3.85 & 14.90 \\
\hline $\mathrm{T}_{3}$ & 10.42 & 15.10 & 1.55 & 5.88 & 9.99 \\
\hline $\mathrm{T}_{5}$ & 16.81 & 21.29 & 1.28 & 12.00 & 4.40 \\
\hline $\mathrm{T}_{6}$ & 7.60 & 12.08 & 1.88 & 3.29 & 18.54 \\
\hline $\mathrm{T}_{7}$ & 9.69 & 13.95 & 1.70 & 5.71 & 14.59 \\
\hline $\mathrm{T}_{8}$ & 10.87 & 17.16 & 1.62 & 6.071 & 12.03 \\
\hline $\mathrm{T}_{9}$ & 13.34 & 19.74 & 1.46 & 8.551 & 8.50 \\
\hline
\end{tabular}

\subsubsection{Influence of Vermiculite on the Physical and Mechanical Properties of Tile Samples}

The bulk densities of fired tile bodies were decreasing with addition of vermiculite from 20 to $35 \%$ wt. (Figure $5 \mathrm{a}$ ). The maximum bulk density was $1.74 \mathrm{~g} / \mathrm{cm}^{3}$ obtained when vermiculite was $20 \%$ wt. while the minimum was $1.28 \mathrm{~g} / \mathrm{cm}^{3}$ obtained when vermiculite was added up to $35 \%$ wt. The bulk density of the control sample which had $0 \%$ wt. vermiculite was $2.15 \mathrm{~g} / \mathrm{cm}$. Tile code $\mathrm{T}_{2}$ had the highest bulk density due to low vermiculite content compared to $\mathrm{T}_{3}, \mathrm{~T}_{4}$ and $\mathrm{T}_{5}$ among the bodies with vermiculite as the only additive (Table 3 ). Decrease of bulk density of tile bodies with addition of vermiculite was mainly caused by low unit weight and density of raw vermiculite [15]. The expanded vermiculite has the density ranging between 0.2 to $0.3 \mathrm{~g} / \mathrm{cm}^{3}$ [16]. These values are low compared to that of clay and kaolin which their bulk density is about $0.8 \mathrm{~g} / \mathrm{cm}^{3}$. Hence, increase of vermiculite content in the samples led to decrease in bulk densities. On the other hand results show that, bending strength of fired ceramic bodies decrease with addition of vermiculite content (Figure 5a). The reference sample had bending strength of $28.86 \mathrm{MPa}$ when the amount of vermiculite in the body was $0 \%$ wt. and this value decreased up to 4.40 MPa when vermiculite content reached $35 \%$ wt. which was the maximum vermiculite content for this study. The maximum bending strength for tile bodies with vermiculite as the only additive material was $14.90 \mathrm{MPa}$ obtained when the vermiculite composition was $20 \%$ wt. This tile body had the strength value close to the required standard for wall tiles while the remaining tile bodies had values ranging between 4.40 and $9.99 \mathrm{MPa}$ which were too far from the required standards (Table 3 ).

According to commercial standards the minimum strengths for wall and floor tiles are $16 \mathrm{MPa}$ and $22 \mathrm{MPa}$ respectively ISO 10545 [17].

Figure $5 \mathrm{~b}$ shows the influence of vermiculite content on water absorption, porosity and linear shrinkage of the fired tile samples. The percentage of porosity of the fired ceramic bodies increase with increase of the vermiculite content. The minimum value was $5.72 \%$ when vermiculite content was $0 \%$ wt. and the highest was $21.29 \%$ obtained when the vermiculite content was $35 \%$ wt. The tile body with $20 \%$ wt. vermiculite had porosity value close to the required international standard for wall and floor tiles applications which is 7 to $12 \%$ of total porosity [8]. Since water absorption is directly related to open porosity, its value also increases with the increase of vermiculite content too. With 
addition of vermiculite the water absorption increased from $2.17 \%$ of the control tile sample up to $16.81 \%$ which was the highest and was obtained when vermiculite content reached $35 \%$ wt. The linear shrinkage of the tile samples increased with the increase of vermiculite content with values ranging from $1.02 \%$ of the control sample $(0 \%$ wt. vermiculite) to $12.00 \%$ when vermiculite was $35 \%$ wt. This is because during firing vermiculite lose water moisture and other volatile (carbon contents) materials, this leads to reduction in particles size and hence dimension.
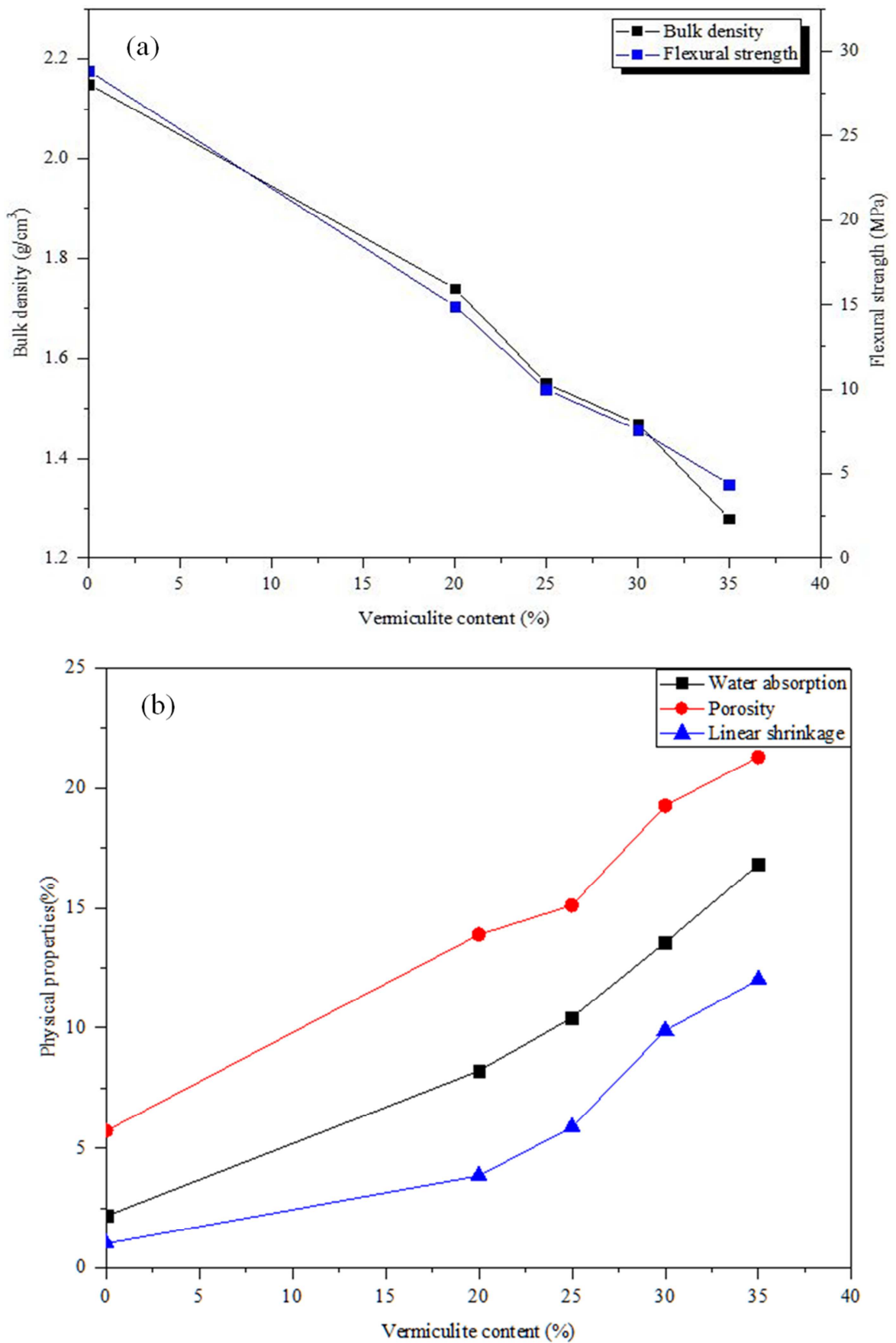

Figure 5. Influence of vermiculite content on the physical and mechanical properties of the fired ceramic bodies (a) bulk density and flexural strength (b) water absorption, porosity and linear shrinkage.

\subsubsection{Influence of RHA on the Physical and Mechanical Properties of Tile Samples}

The physical and mechanical properties of tile bodies $\left(\mathrm{T}_{6}\right.$, $\mathrm{T}_{7}, \mathrm{~T}_{8}$ and $\mathrm{T}_{9}$ ) with both vermiculite and RHA are shown in Table 3 and Figure 6. Similar correlation was observed on the bulk density of the tile bodies which was decreasing with increase of RHA content. The control tile sample had the bulk density of $2.15 \mathrm{~g} / \mathrm{cm}^{3}$ when RHA was zero and this value decreased up to $1.46 \mathrm{~g} / \mathrm{cm}^{3}$ when RHA was added up to $20 \%$ wt. together with $35 \%$ wt. vermiculite (Figure $6 \mathrm{a}$ ). The maximum bulk density of samples with RHA was $1.88 \mathrm{~g} / \mathrm{cm}^{3}$ obtained when RHA was added up to $5 \%$ wt. together with 
$20 \%$ wt. vermiculite. Bulk densities of ceramic bodies with both vermiculite and RHA are higher than those with vermiculite only because vermiculite is more porous than RHA. The incorporation of RHA in the range of 5 to $20 \% \mathrm{wt}$. in the tile composition had a favorable feature in bulk production in view of the enhancement of the densification process as well as the wide vitrification range of body mixes. According to [18] the solid density of the clay samples showed a steady reduction from 2.9 to $2.6 \mathrm{~g} / \mathrm{cm}^{3}$ as the RHA addition increased which correlates with the results obtained in this study. Since the bulk density is directly proportional to strength of a material the addition of both vermiculite and RHA caused the bending strengths of the fired ceramic bodies to decrease from $28.86 \mathrm{MPa}$ when the additives were $0 \%$ wt. to $8.50 \mathrm{MPa}$ when RHA was $20 \%$ wt. and with $35 \%$ wt. vermiculite (Figure 6a). From these results, the maximum bending strength of the bodies with RHA and vermiculite additives was $18.54 \mathrm{MPa}$ obtained when RHA was 5\% wt. and with $20 \%$ wt. vermiculite. At least the bending strength for this body was too close to the required standards for wall and floor tiles applications, $16 \mathrm{MPa}$ and $22 \mathrm{MPa}$ respectively according to ISO 10545-4 [17].
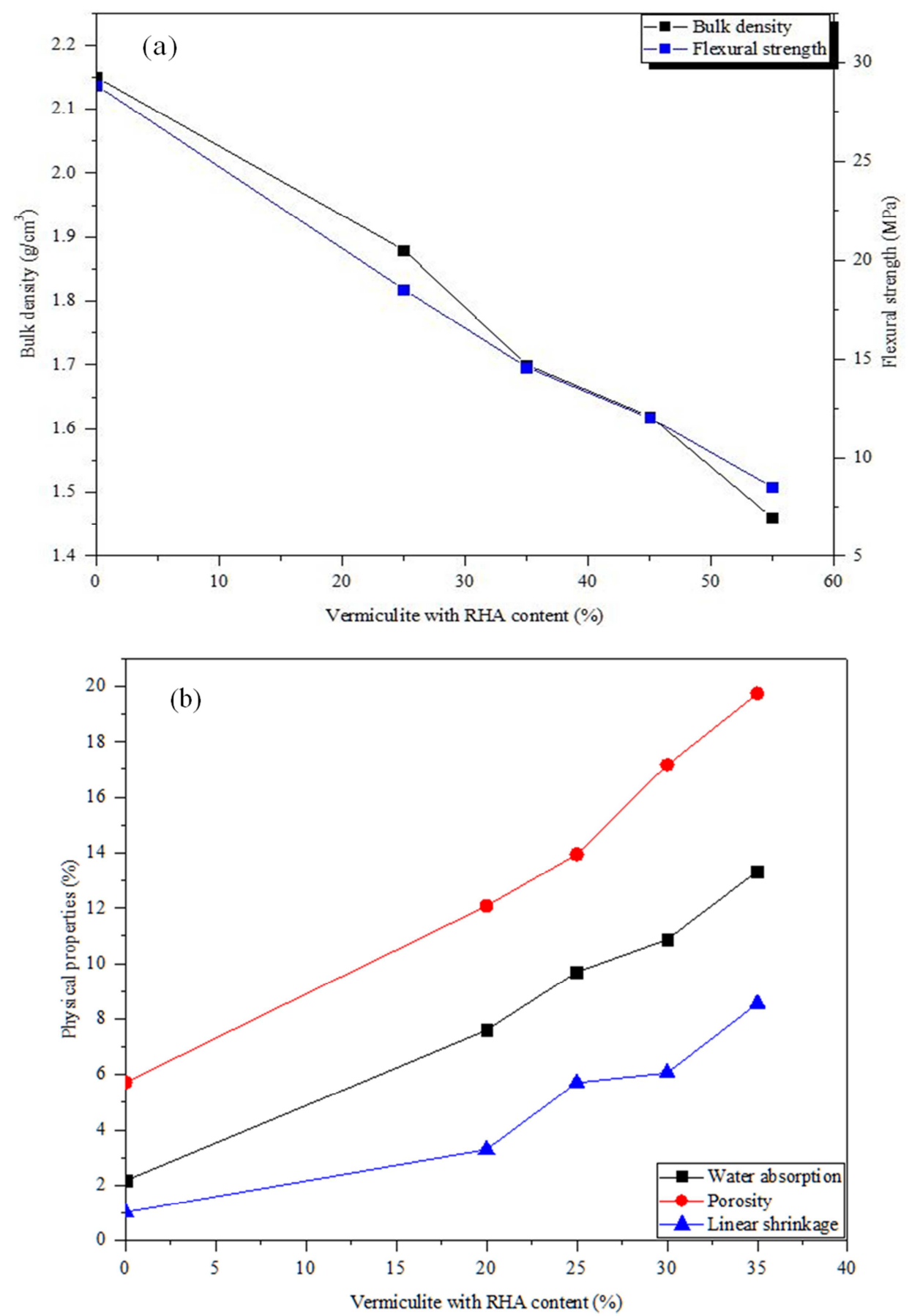

Figure 6. Influence of vermiculite and RHA content on the physical and mechanical properties of the fired ceramic bodies (a) bulk density and flexural strength (b) water absorption, porosity and linear shrinkage. 
It is clearly observed that tile samples with both vermiculite and RHA have high bending strength compared to the tile bodies without RHA because more glass was formed due to the introduction of RHA which filled the pores, in this way the porosity and water absorption decreased, hence bulk density and finally the strength of the tile bodies' increased. Partial replacement of quartz by rice husk ash (RHA) was expected to reduce the possibility of $\beta$ to $\alpha$ phase inversion of quartz which occurs at $573^{\circ} \mathrm{C}$ during cooling which results into decrease of quartz particle volume and may lead to cracks in the ceramic body [19]. According to literature information the progressive substitution of quartz by RHA in a conventional ceramic body composition resulted in an early vitrification of the mixes, while complete replacement of quartz by RHA drastically reduced both the maturing temperature and the percentage of thermal expansion, and increased the strength marginally [20]. Figure $6 \mathrm{~b}$ shows the relationship between percentage of porosity, water absorption and linear shrinkage with addition of both vermiculite and RHA. Results show that; with addition of both vermiculite and RHA percentage of porosity, water absorption capacity and linear shrinkage increased from 5.72 to $19.74 \%, 2.17$ to $13.34 \%$ and 1.02 to $8.55 \%$ respectively. But these values are low compared to that of tile bodies without RHA. The linear shrinkage of tile bodies with both vermiculite and RHA is low due to the addition of RHA. When RHA was added, the quartz starts to dissolute rapidly and produces more silica content to assist feldspar in dissolving the particles in the tile bodies [21], this reduced the pores and hence lowering of the shrinkage. According to [18], the use of RHA in ceramic samples led to a steady reduction in linear shrinkage from 8.7 to $8.4 \%$ as the quantity of rice husks addition increased from 0 to $40 \%$ wt. Generally it can be revealed from the graphs that; with addition of vermiculite and RHA the porosity, water absorption and linear shrinkage were increased this caused a decrease in bending strength and bulk density. This is because vermiculite and RHA are porous materials with low density compared to clay and kaolin. Also vermiculite is a light material which expands at higher temperature and this result into the development of cracks due to formation of vacancy defects usually created when the body cools after firing. However ceramic bodies with both vermiculite and RHA had better physical and mechanical properties compared to those with vermiculite only. Theoretically, when the porosity increases, flexural strength and bulk density was expected to decrease and that was exactly what happened (Figure 7).

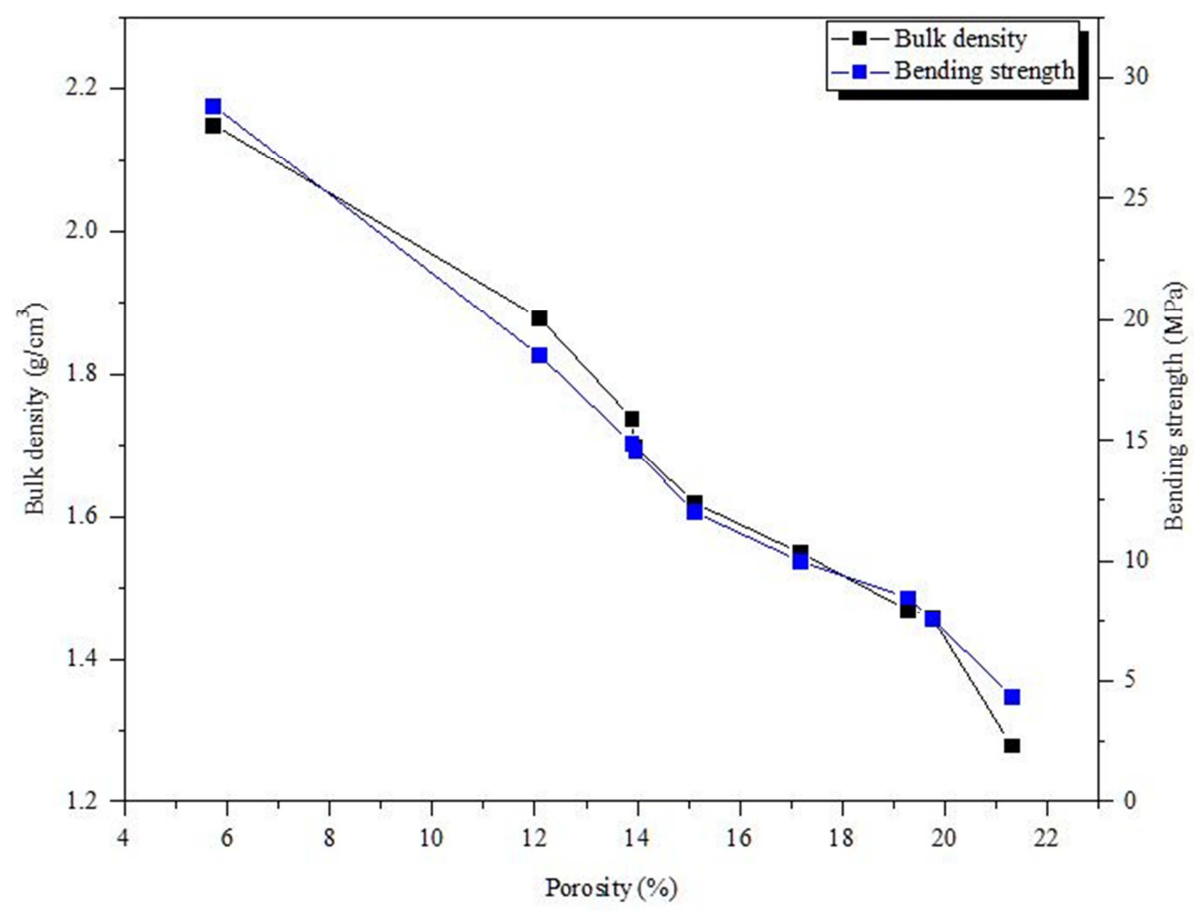

Figure 7. The effect of porosity on bulk density and flexural strength of the tile sample.

\section{Conclusion}

The following conclusion can be derived according to test results. With addition of vermiculite and RHA the porosity, water absorption and linear shrinkage of the fired bodies increased while the bending strength and bulk density decreased. Ceramic bodies with both vermiculite and RHA had better physical and mechanical properties compared to those with vermiculite only. Among the studied compositions apart from the reference sample, tile bodies made from blend containing $20 \% \mathrm{wt}$. vermiculite and $5 \% \mathrm{wt}$. RHA were found to have the best properties for the production of ceramic tiles. For this combination the percentage of porosity, water absorption and linear shrinkage were $12.08 \%, 7.60 \%$ and 
$3.29 \%$ while the bulk density and bending strength were 1.88 $\mathrm{g} / \mathrm{cm}^{3}$ and $18.84 \mathrm{MPa}$. These values were close to the required standards of wall and floor tiles which indicate that vermiculite and RHA are suitable and promising raw materials for production of ceramic tiles. Further studies on the strength and insulating properties of ceramic tiles should be done by analyzing the effects of addition of other agricultural wastes on ceramic tiles as well as reducing the iron content in vermiculite samples. The presence of high amount of Iron in vermiculite increases thermal conductivity of the final fired body which also affects thermal comfort of the tiles. Depending on materials selection, batch formulations and forming processes (processing techniques) it is possible to obtain porous ceramics with high mechanical strength.

\section{Acknowledgements}

The authors would like to express their thanks for the financial support provided by British Gas (BG)-Tanzania.

\section{References}

[1] Akwilapo, L. D. and K. Wiik, Ceramic properties of Pugu kaolin clays. Part I: Porosity and modulus of rupture. Bulletin of the Chemical Society of Ethiopia, 2003. 17 (2).

[2] Carty, W. M. and U. Senapati, Porcelain-raw materials, processing, phase evolution, and mechanical behavior. Journal of the American Ceramic Society, 1998. 81 (1): p. 3-20.

[3] Hassan, U. and M. Maharaz, Influence of Addition of Rice Husk Ash on Porcelain Composition. Science World Journal, 2015. 10 (1): p. 7-16.

[4] Umut Önen, E. E., Şenol Yılmaz, Th e Investigation for the Possibilities of Construction Material Production from Vermiculite. UCTEA Chamber of Metallurgical \& Materials Engineers Proceedings Book, 2016.

[5] Silva Jr, C., et al., Preparation of glass-ceramics from vermiculite clay mineral. Journal of Ceramic Processing Research, 2014. 15 (5): p. 360-365.

[6] Escalera, E., et al., The production of porous brick material from diatomaceous earth and Brazil nut shell ash. Construction and Building Materials, 2015. 98: p. 257-264.

[7] Hamisi, H., et al., Influence of firing temperature on physical properties of same clay and pugu kaolin for ceramic tiles application. International Journal of Materials Science and Applications, 2014. 3 (5): p. 143-146.

[8] Vieira, C. and S. Monteiro, Effect of grog addition on the properties and microstructure of a red ceramic body for brick production. Construction and Building Materials, 2007. 21 (8): p. 1754-1759.

[9] Haslinawati, M., et al., Effect of temperature on ceramic from rice husk ash. International Journal of Basic \& Applied Sciences, 2009.9 (9): p. 22-25.

[10] Della, V. P., I. Kühn, and D. Hotza, Rice husk ash as an alternate source for active silica production. Materials Letters, 2002. 57 (4): p. 818-821.

[11] Marwa, E. M. M., et al., Mineralogical and chemical characterization of some vermiculites from the Mozambique Belt of Tanzania for agricultural use. Clay Minerals, 2009. 44 (1): p. 1-17.

[12] Escalera, E., Characterization and preparation of lightweight silica based ceramics for building applications, 2015, Luleå tekniska universitet.

[13] Farooque, K., et al., Characterization and utilization of rice husk ash (RHA) from rice mill of Bangladesh. Bangladesh Journal of Scientific and Industrial Research, 2009. 44 (2): p. 157-162.

[14] Zhang, M.-H. and V. M. Malhotra, High-performance concrete incorporating rice husk ash as a supplementary cementing material. ACI Materials Journal, 1996. 93: p. 629636.

[15] Sutcu, M., Influence of expanded vermiculite on physical properties and thermal conductivity of clay bricks. Ceramics International, 2015. 41 (2): p. 2819-2827.

[16] Önen, U., E. Ercenk, and Ş. Yılmaz, Th e Investigation for the Possibilities of Construction Material Production from Vermiculite. Chamber of Metallurgical \& Materials Engineers Proceedings Book, 2016.

[17] Matteucci, F., M. Dondi, and G. Guarini, Effect of soda-lime glass on sintering and technological properties of porcelain stoneware tiles. Ceramics International, 2002. 28 (8): p. 873880 .

[18] Manukaji John, U., The Insulating Effects of Rice Husks Addition on the Mechanical Properties of Clay Samples from Kaduna State Nigeria.

[19] Martín-Márquez, J., J. M. Rincón, and M. Romero, Effect of firing temperature on sintering of porcelain stoneware tiles. Ceramics International, 2008. 34 (8): p. 1867-1873.

[20] Prasad, C., K. N. Maiti, and R. Venugopal, Effect of rice husk ash in whiteware compositions. Ceramics International, 2001. 27 (6): p. 629-635.

[21] Prasad, C., K. N. Maiti, and R. Venugopal, Effect of substitution of quartz by rice husk ash and silica fume on the properties of whiteware compositions. Ceramics International, 2003. 29 (8): p. 907-914. 